\title{
In utero exposure to di-(2-ethylhexyl) phthalate induces metabolic disorder and increases fat accumulation in visceral depots of $\mathrm{C} 57 \mathrm{BL} / 6 \mathrm{~J}$ mice offspring
}

\author{
HAILUN GU ${ }^{1}$, YALI LIU ${ }^{2}$, WEI WANG ${ }^{1}$, LIFENG DING ${ }^{1}$, WEIPING TENG ${ }^{3}$ and LI LIU ${ }^{4}$ \\ ${ }^{1}$ Department of Orthopedics, Shengjing Hospital, China Medical University, Shenyang, Liaoning 110004; \\ ${ }^{2}$ Department of Medical Laboratory Testing, Liaoning Medical Vocational College, Shenyang, Liaoning 110101; \\ ${ }^{3}$ Liaoning Provincial Key Laboratory of Endocrine Diseases, Department of Endocrinology and Metabolism, \\ The First Affiliated Hospital of China Medical University, Shenyang, Liaoning 110001; \\ ${ }^{4}$ Department of Nutrition and Food Hygiene, School of Public Health, China Medical University, \\ Shenyang, Liaoning 110122, P.R. China
}

Received July 3, 2015; Accepted August 11, 2016

DOI: $10.3892 / e t m .2016 .3820$

\begin{abstract}
Excessive visceral fat accumulation is associated with metabolic disorders. Di-(2-ethylhexyl) phthalate (DEHP), a candidate environmental obesogen, affects lipid metabolism and adipogenesis. Perinatal exposure to DEHP may be associated with metabolic disorders of dams and offspring. The aim of the present study was to explore the effects of exposure of pregnant dams to DEHP on the metabolism and fat distribution of their offspring, and to determine the mechanisms for these effects. Pregnant C57BL/6J mice were administered DEHP via gavage $(0.05$ or $500 \mathrm{mg} / \mathrm{kg} /$ day $)$ from gestational days 1-19. Pups were sacrificed at nine weeks of age. Serum leptin, insulin, lipid and fasting glucose levels, and the weights of the inguinal (subcutaneous) and gonadal (visceral) fat pads were determined. mRNA expression levels of two developmental genes, T-box 15 (Tbx15) and glypican 4 (Gpc4) were detected in fat tissues. A $100 \%$ abortion rate was exhibited in $500 \mathrm{mg} / \mathrm{kg}$ DEHP-treated dams, whereas exposure to $0.05 \mathrm{mg} / \mathrm{kg}$ DEHP did not affect reproductive outcomes. Pups from the $0.05 \mathrm{mg} / \mathrm{kg}$ exposure group were used for subsequent experimentation. Serum leptin, insulin, lipid and fasting glucose concentrations
\end{abstract}

Correspondence to: Dr Hailun Gu, Department of Orthopedics, Shengjing Hospital, China Medical University, 36 Sanhao Street, Heping, Shenyang, Liaoning 110004, P.R. China

E-mail: guhailun_@163.com

Professor Weiping Teng, Liaoning Provincial Key Laboratory of Endocrine Diseases, Department of Endocrinology and Metabolism, The First Affiliated Hospital of China Medical University, 155 Nanjing North Street, Shenyang, Liaoning 110001, P.R. China

E-mail: twp@vip.163.com

Key words: di-(2-ethylhexyl) phthalate, visceral fat, fat distribution, T-box 15, glypican 4 in these pups were significantly higher than those of control pups $(\mathrm{P}<0.05)$. Although no significant change in body weight was detected, the visceral fat weights of DEHP-exposed pups were significantly higher than those of control pups $(\mathrm{P}<0.05)$. Compared with controls, mRNA expression levels of Tbx15 in subcutaneous fat and $G p c 4$ in visceral fat were significantly increased among DEHP-exposed pups $(\mathrm{P}<0.01)$. The present results suggest that in utero exposure to an environmentally safe dose of DEHP may lead to excessive visceral fat accumulation and metabolic disorders in offspring and that aberrant expression of Tbx15 and Gpc4 may have an important role in these effects.

\section{Introduction}

Distribution of white adipose tissues in humans is associated with metabolic disorders. Individuals who are peripherally obese (fat accumulation predominantly in the gluteofemoral region) are at little or no risk of developing metabolic disease, whereas individuals who are centrally obese (fat distribution predominantly in visceral depots) are prone to developing metabolic complications (1). However, the underlying mechanisms that regulate fat distribution and link excess visceral fat to metabolic complications are yet to be elucidated.

Environmental obesogens are chemical compounds that promote or exacerbate the development of obesity and its associated health outcomes (2) by disrupting or interfering with critical pathways associated with energy balance, adipogenesis and lipid metabolism (3). Phthalates are a class of candidate obesogens that are ingested in food. Phthalate metabolites have been detected in $>80 \%$ of the population and fetal exposure levels are readily detectable (4-6). In a previous cross-sectional study, urinary phthalate metabolite concentrations were demonstrated to be associated with an increased waist circumference and insulin resistance in adult males in the USA $(7,8)$. This correlation indicates that increased phthalate exposure may be associated with increased abdominal obesity and fat distribution. In addition, there are age and sex differ- 
ences in the association between phthalate exposure and obesity $(9,10)$. For example, male children and adolescents are at high risk for obesity associated with urinary low molecular weight phthalate metabolites, whereas adults are at high risk for obesity associated with high molecular weight phthalate metabolites (9). Moreover, associations were positive for low molecular weight phthalate metabolites with BMI z-score in boys $>10$ years of age, but no association was detected in girls $<10$ years of age (10).

Di-(2-ethylhexyl) phthalate (DEHP), which is a phthalate ester, is predominately used as an industrial plasticizer and is found in cosmetics, industrial paints and solvents (11). The presence of DEHP metabolites in urine is associated with adiposity and insulin resistance in children (12). Previous studies have reported that perinatal exposure to DEHP may induce obesity and metabolic disorders in mice $(13,14)$; however, the mechanisms underlying these associations are yet to be investigated.

T-box 15 (Tbx15) and glypican 4 (Gpc4) are developmental genes that have roles in the origins of obesity and body fat distribution in mice and humans (15). In humans, Tbx15 expression is negatively correlated with waist/hip ratio (16). Low levels of Tbx15 mRNA and high levels of Gpc4 mRNA in visceral adipose tissue, and low levels of $G p c 4$ mRNA and high levels of Tbx15 mRNA in subcutaneous adipose tissue appear to be associated with a high waist/hip ratio (15) and, therefore, may be associated with obesity and fat distribution. These genes may be correlated with an increased risk of developing metabolic and cardiovascular complications (15).

In utero exposure to endocrine-disrupting chemicals may alter adipose tissue development by affecting the number, size, and distribution of adipocytes formed, as well as larger regulatory systems associated with body weight homeostasis (17). Therefore, it was hypothesized in the present study that in utero exposure to DEHP may, in part, affect obesity and fat distribution by altering the expression of Tbx15 and Gpc4 in murine offspring. The effects of exposure to DEHP in pregnant dams on their 9-week-old offspring was investigated by measuring: i) Serum leptin, insulin, lipid, and glucose concentrations; ii) body weight and adipose tissue deposition; and iii) mRNA expression levels of Tbx15 and Gpc4 in subcutaneous and visceral adipose tissues.

\section{Materials and methods}

Reagents. DEHP, serum triglyceride determination kit (TR0100) and cholesterol quantitation kit (MAK043) were purchased from Sigma-Aldrich (Merck Millipore, Darmstadt, Germany). Leptin ELISA kit (EK0438) was obtained from Boster Biological Technology (Wuhan, China), and insulin ELISA kit (EZRMI-13K) was purchased from Merck Millipore (Shanghai, China). RNAiso Plus, PrimeScript RT Perfect Real Time reagent kit and SYBR Premix Ex Taq II kit (Tli RNaseH Plus) were purchased from Takara Biotechnology Co., Ltd. (Dalian, China). Primers were synthesized by Sangon Biotech Co., Ltd. (Shanghai, China).

Animals. Male $(\mathrm{n}=25)$ and female $(\mathrm{n}=50)$ C57BL/6J mice (age, 8 weeks; weight: male, $21.9 \pm 1.0 \mathrm{~g}$; female, 19.6 $\pm 0.9 \mathrm{~g}$ ) were purchased from the Animal Center of China Medical
University (Shenyang, China). Mice were kept at a controlled temperature of $20 \pm 2^{\circ} \mathrm{C}$ and a relative humidity of $50 \pm 10 \%$ with a 12-h light/dark cycle. Mice were provided water and a standard chow diet containing $10 \% \mathrm{kcal}$ from fat ad libitum. Animal procedures were conducted according to an animal protocol approved by the Institutional Animal Care and Use Committee of China Medical University.

Fetal exposure to DEHP. A total of 25 male and 50 female mice (gender ratio, 1:2) were mated overnight. Females were examined for a copulation plug the following day, which was designated as gestational day (GD) 1. Pregnant females were randomly divided into three groups (F0 control, F0 DEHP0.05 and F0 DEHP500) and exposed to various concentrations of DEHP (0, 0.05 and $500 \mathrm{mg} / \mathrm{kg} /$ day). DEHP (diluted in olive oil) or vehicle (olive oil) was administered via gavage every $24 \mathrm{~h}$ from GD1 to GD19. Food intake of F0 dams was recorded weekly. Spontaneous abortion was determined in dams that did not deliver. Pups (F1 control, n=29 (female/male ratio, 15:14) and F1 DEHP0.05, $\mathrm{n}=30$ (female/male ratio, 14:16) were maintained with their dams and weaned at three weeks of age. Pups were subsequently fed a standard diet until nine weeks of age.

Serum measurements. Blood samples of F1 offspring were harvested from the abdominal aorta at nine weeks of age. Samples were centrifuged at $1,000 \times \mathrm{g}$ for $15 \mathrm{~min}$ at room temperature and stored at $-20^{\circ} \mathrm{C}$ prior to analysis. Levels of serum leptin and insulin were determined using ELISA kits. Serum triglyceride and total cholesterol levels were determined using commercial kits. Serum glucose concentration was measured via the glucose oxidase method (18). All experimental protocols were performed according to the manufacturers' protocols. All data were obtained from three independent experiments.

Adipose tissue collection. F1 offspring were anesthetized with ether (Tianjin Guangfu Fine Chemical Research Institute, Tianjin, China) and sacrificed at nine weeks of age via cervical dislocation. Gonadal and inguinal fat pads were immediately removed, weighed, frozen in liquid nitrogen and stored at $-80^{\circ} \mathrm{C}$ prior to RT-qPCR analysis. Gonadal and inguinal fat pads were representative of visceral and subcutaneous fat, respectively.

$R T-q P C R$. Total RNA of gonadal and inguinal fat pads was extracted using RNAiso Plus, according to the manufacturer's protocol. RT-qPCR reactions were performed using the ABI Prism 7500 system (Thermo Fisher Scientific, Inc., Waltham, MA, USA) as described previously (19). Briefly, RT was performed with a reaction mixture containing $2 \mu \mathrm{l} 5 \mathrm{X}$ PrimeScript buffer, $0.5 \mu$ 1 PrimeScript RT Enzyme Mix, $0.5 \mu 1$ Oligo dT Primer $(50 \mu \mathrm{M})$ and/or $0.5 \mu \mathrm{l}$ Random hexamers $(100 \mu \mathrm{M})$ and $500 \mathrm{ng}$ mRNA. The mixture was maintained for $5 \mathrm{~min}$ at $37^{\circ} \mathrm{C}$ followed by $5 \mathrm{sec}$ at $85^{\circ} \mathrm{C}$ and final hold at $4^{\circ} \mathrm{C}$. Subsequently, each qPCR reaction mixture contained $10 \mu 1$ 2X SYBR Premix Ex Taq II, $0.8 \mu$ l forward and reverse primers (10 $\mu \mathrm{mol} / \mu \mathrm{l}), 0.4 \mathrm{ml}$ Rox Reference Dye II (50X) and $2 \mu \mathrm{l}$ cDNA. Thermal cycling was performed to amplify the respective targets in a total volume of $20 \mu \mathrm{l}$ : Initial denatur- 
ation at $95^{\circ} \mathrm{C}$ for $30 \mathrm{sec}$ for 1 cycle, followed by denaturation at $95^{\circ} \mathrm{C}$ for $5 \mathrm{sec}$ and annealing and extension $60^{\circ} \mathrm{C}$ for $34 \mathrm{sec}$ for 40 cycles. $\beta$-actin was used as the endogenous control gene. RT-qPCR data were analyzed using the $2^{-\Delta \Delta C q}$ method (20). All PCR reactions were performed in triplicate. Primers were designed as follows: $\beta$-actin, forward 5'-CATCCGTAAAGA CCTCTATGCCAAC-3' and reverse 5'-ATGGAGCCACCG ATCCACA-3'; Gpc4, forward 5'-AGAGCAACGCCCAAC CAC-3' and reverse 5'-GCCATTCCAGCAGTCATC-3'; and Tbx15, forward 5'-AGCTTCTGGAGACACCTGGATGA-3' and reverse 5'-CGTGGACTCGAGGCTGGTATTTA-3'.

Statistical analysis. Data are expressed as mean \pm standard deviation. Statistical analyses were performed using the two-tailed unpaired Student's t-test with unequal variance or one-way analysis of variance and Spearman's correlation analysis using SPSS 13.0 software (SPSS Inc., Chicago, IL, USA). $\mathrm{P}<0.05$ was considered to indicate a statistically significant difference.

\section{Results}

Effects of exposure to DEHP on reproductive outcomes of $\mathrm{FO}$ dams. As indicated in Table I, the food intake of pregnant mice was not significantly altered by DEHP exposure. However, reproductive outcome was impaired in dams exposed to a high dose $(500 \mathrm{mg} / \mathrm{kg})$ of DEHP. A $100 \%$ abortion rate was exhibited by the F0 DEHP500 group, whereas no adverse reproductive effect was demonstrated by the F0 DEHP0.05 group. Therefore, the offspring of the F0 DEHP0.05 group (F1 DEHP0.05) and of the control mice (F1 control) were used for subsequent stages of the present study.

Effects of in utero exposure to DEHP on serum leptin and insulin concentrations in F1 offspring. As shown in Fig. 1, serum leptin (female, $11.09 \pm 1.53 \mathrm{ng} / \mathrm{ml}$; male, $11.11 \pm 1.23 \mathrm{ng} / \mathrm{ml}$ ) and insulin (female, $0.29 \pm 0.08 \mathrm{ng} / \mathrm{ml}$; male, $0.28 \pm 0.05 \mathrm{ng} / \mathrm{ml}$ ) concentrations in the F1 DEHP0.05 group were significantly higher than those in the F1 control group (leptin: female, $9.95 \pm 1.14 \mathrm{ng} / \mathrm{ml}$; male, $9.86 \pm 1.19 \mathrm{ng} / \mathrm{ml}$; and insulin: female, $0.23 \pm 0.06 \mathrm{ng} / \mathrm{ml}$; male, $0.23 \pm 0.07 \mathrm{ng} / \mathrm{ml} ; \mathrm{P}<0.05)$. No significant differences were observed between female and male F1 offspring.

Effect of in utero exposure to DEHP on body weight, fat distribution, serum lipid levels, and glucose concentrations in F1 offspring. In utero exposure to DEHP had no significant effect on the body weights (Fig. 2A) or subcutaneous fat weights (Fig. 2B) of F1 offspring in the DEHP0.05 group compared with the control group. However, as shown in Fig. 2C, visceral fat weights in the F1 DEHP0.05 group (female, 0.36 $\pm 0.10 \mathrm{~g}$; male, $0.41 \pm 0.10 \mathrm{~g}$ ) were significantly higher than those in the F1 control group (female, $0.29 \pm 0.05 \mathrm{~g}$; male, $0.30 \pm 0.05 \mathrm{~g} ; \mathrm{P}<0.05$ ). Consistent with this increase in visceral fat mass, serum total triglycerides, total cholesterol, and fasting glucose levels were significantly increased by $\sim 8,13$, and $16 \%$, respectively, compared with the controls (Fig. 2D-F; P<0.05). No significant difference was observed between female and male F1 offspring.

Effects of in utero exposure to DEHP on the mRNA expression levels of Tbx15 and Gpc4 in subcutaneous and visceral
Table I. Reproductive outcome of F0 dams treated with DEHP from gestational day 1 to 19 .

\begin{tabular}{lccc}
\hline & \multicolumn{3}{c}{ DEHP (mg) } \\
\cline { 2 - 4 } Criteria & 0 & 0.05 & 500 \\
\hline Pregnant dams (n) & 6 & 6 & 7 \\
Food intake (g/day) & $4.9 \pm 0.5$ & $5.0 \pm 0.8$ & $5.1 \pm 0.7$ \\
Delivery (n) & 6 & 6 & 0 \\
Abortion (\%) & 0 & 0 & 100 \\
F1 offspring (n) & 29 & 30 & 0 \\
F1 offspring size & $4.83 \pm 1.94$ & $4.29 \pm 1.80$ & - \\
F1 females (n) & 15 & 14 & - \\
F1 males (n) & 14 & 16 & - \\
\hline
\end{tabular}

Data are presented as mean \pm standard deviation, or as stated. DEHP, di (2-ethylhexyl) phthalate.

fat in F1 offspring. As shown in Fig. 3A, Tbx15 mRNA expression levels in subcutaneous fat in the F1 control and F1 DEHP0.05 groups were significantly higher than those in visceral fat $(\mathrm{P}<0.01)$. The expression of Tbx15 mRNA expression levels in subcutaneous fat were significantly increased in the F1 DEHP0.05 group compared with the F1 control group $(\mathrm{P}<0.01)$, whereas no significant increase was observed in visceral fat. Expression levels of $G p c 4$ mRNA in subcutaneous fat in the control and DEHP-treated groups were significantly lower than those in visceral fat $(\mathrm{P}<0.01$; Fig. 3B). Compared with the F1 control group, the expression of Gpc4 mRNA in visceral fat was significantly upregulated in the F1 DEHP0.05 group $(\mathrm{P}<0.01)$, but no significant increase was detected in the subcutaneous fat.

Association between leptin, insulin, serum lipid and glucose concentration, and $m R N A$ expression levels of Tbx 15 and Gpc4 in subcutaneous and visceral fat of F1 offspring. As shown in Table II, Spearman's correlation analysis demonstrated that serum leptin concentration was positively correlated with Tbx15 and Gpc4 mRNA in visceral fat. Serum insulin and glucose concentrations were positively correlated with $T b x 15$ mRNA in subcutaneous fat, as well as $G p c 4$ mRNA in visceral fat. Serum total triglyceride was positively correlated with Tbx15 mRNA in subcutaneous fat, whereas total cholesterol was positively correlated with Gpc4 mRNA in visceral fat.

\section{Discussion}

In the present study, DEHP was administered to pregnant C57BL/6J mice by gavage. DEHP was absorbed through the intestines, a route that mimics one of the most prominent exposure routes in humans (11). DEHP was delivered at 0.05 and $500 \mathrm{mg} / \mathrm{kg} /$ day. The lower dose $(0.05 \mathrm{mg} / \mathrm{kg} /$ day $)$ is considered to be a 'safe dose' for humans and is within the tolerable daily intake (TDI) (21). In contrast, the higher dose (500 mg/kg/day) has caused adverse reproductive and developmental effects in previous animal studies (22). The principal results of the present study were as follows. Firstly, 
A

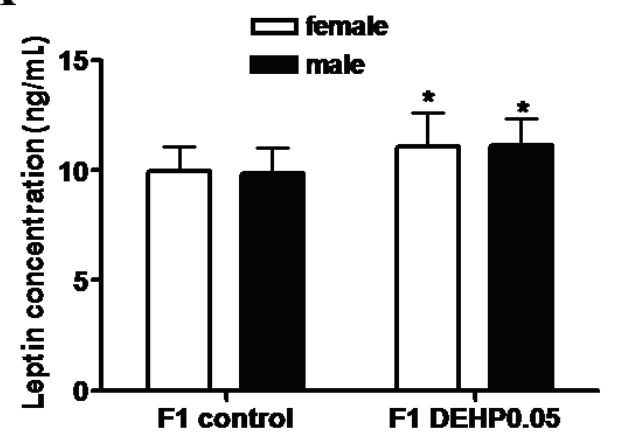

B

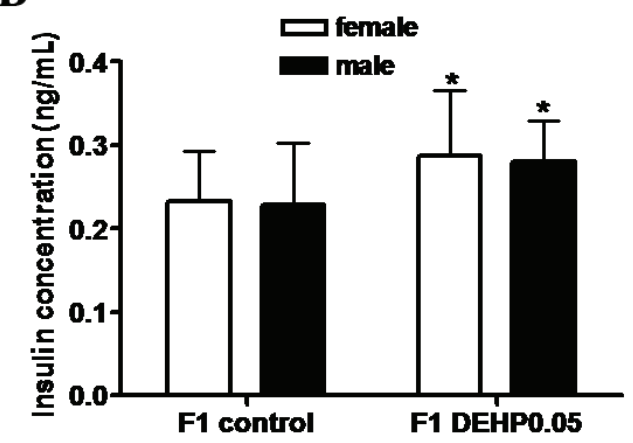

Figure 1. Effects of in utero exposure to DEHP on serum (A) leptin and (B) insulin concentrations of F1 offspring. DEHP or vehicle (olive oil) was administered to pregnant females by gavage $(0.05 \mathrm{mg} / \mathrm{kg})$ every $24 \mathrm{~h}$ from GD1 to 19 . F1 offspring were weaned at three weeks of age and fed a standard diet through nine weeks of age. Results are shown as the mean \pm standard deviation $(\mathrm{n}=15$ female and 14 male in the F1 control group, $\mathrm{n}=14$ female and 16 male in the F1 DEHP0.05 group). DEHP, di-(2-ethylhexyl) phthalate; GD, gestational day. "P<0.05 vs. the F1 control group.

A

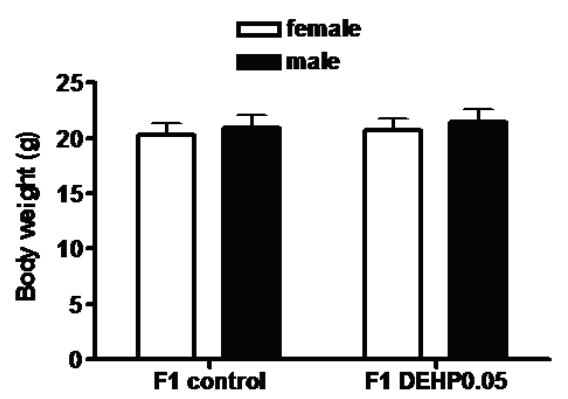

C

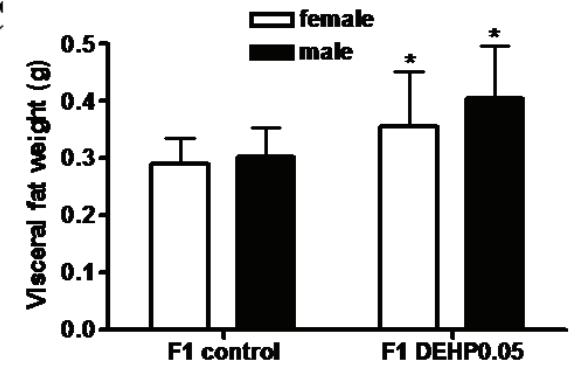

$\mathbf{E}$

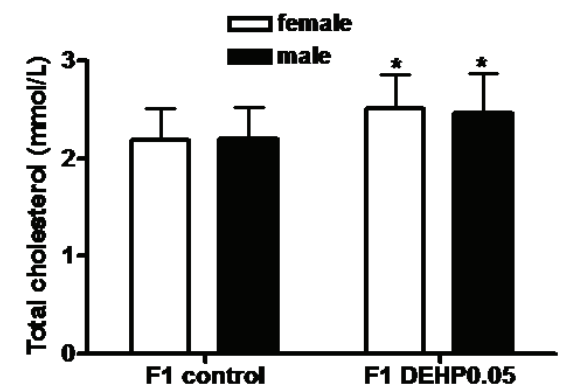

B

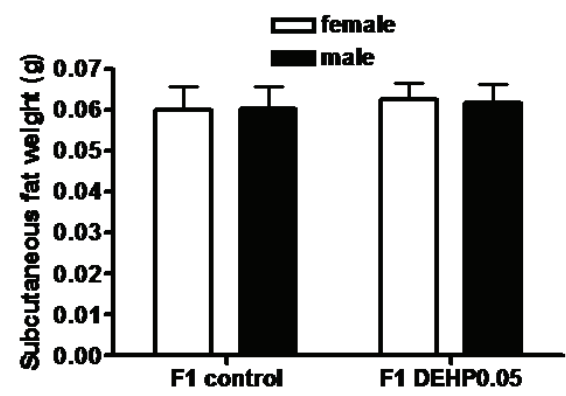

D

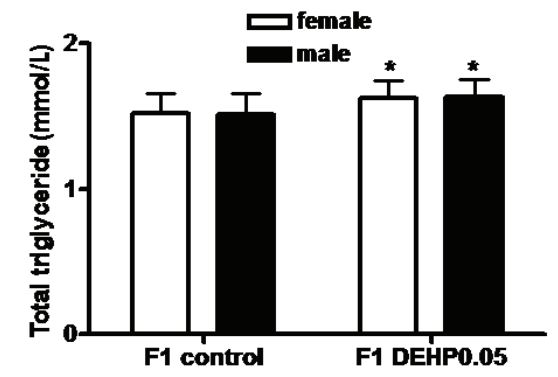

$\mathbf{F}$

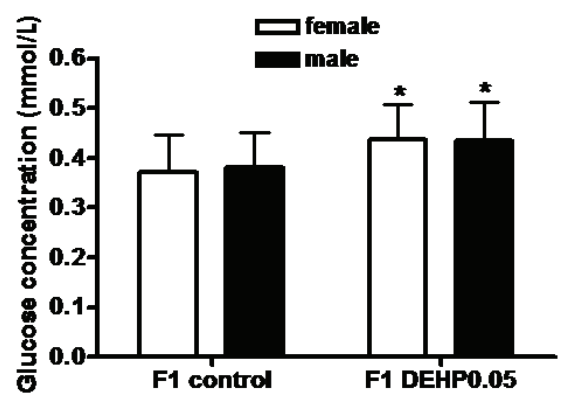

Figure 2. Effects of in utero exposure to DEHP on body weight, fat distribution, and serum lipid and glucose concentration in F1 offspring. (A) Body weight, (B) weight of subcutaneous fat, (C) weight of visceral fat, (D) total triglyceride levels, (E) total cholesterol levels, and (F) serum fasting glucose levels. Results are shown as the mean \pm standard deviation (F1 control group: female, $n=15$ and male, $n=14 ; F 1$ DEHP0.05: female, $n=14$ and male, $n=16$ ). DEHP, di-(2-ethylhexyl) phthalate. ${ }^{*} \mathrm{P}<0.05$ vs. the F1 control group.

exposure to $0.05 \mathrm{mg} / \mathrm{kg}$ DEHP did not significantly affect the food intake or reproductive capacity of F0 dams. Secondly, the weight of visceral fat and serum leptin, insulin, serum lipid, and glucose concentrations were significantly elevated in F1 offspring following in utero exposure to $0.05 \mathrm{mg} / \mathrm{kg}$ DEHP. Thirdly, expression levels of Tbx15 mRNA in subcutaneous fat and Gpc4 mRNA in visceral fat were significantly upregulated in F1 offspring exposed to $0.05 \mathrm{mg} / \mathrm{kg}$ DEHP in utero.

Previous studies have reported that DEHP is able to induce a dose-dependent decrease in mouse fertility (23), and affect reproductive outcomes in female mice (24). In the present study, no significant decline in fertility was exhibited by F0 dams treated with $0.05 \mathrm{mg} / \mathrm{kg}$ DEHP; however, the abortion 
A

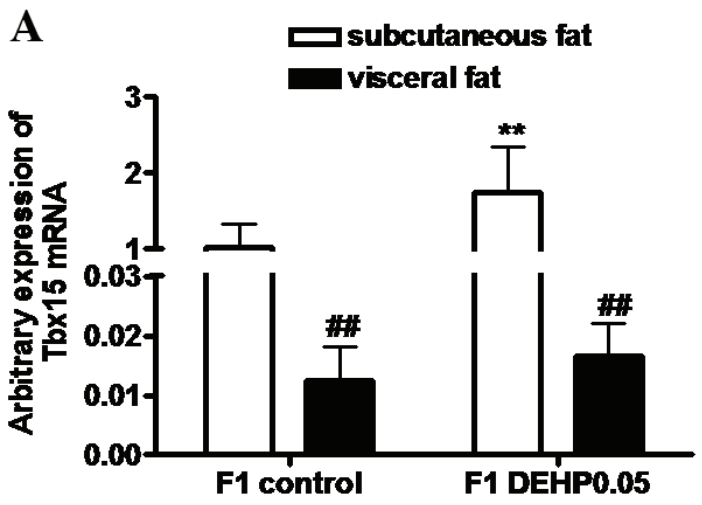

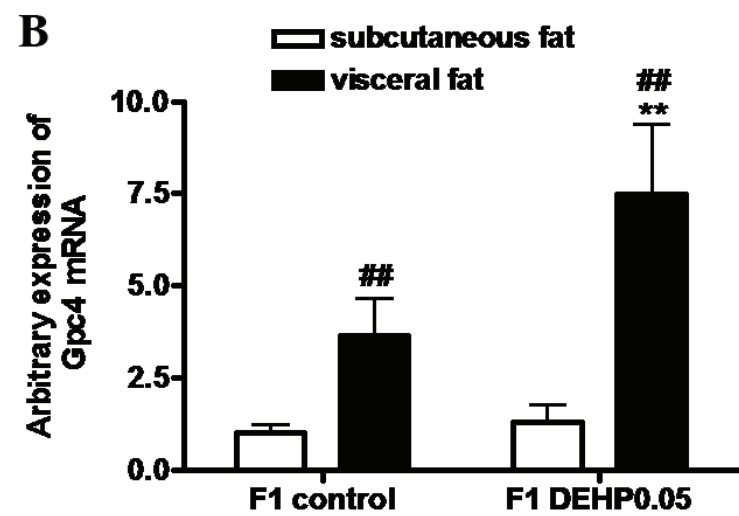

Figure 3. Effects of in utero exposure to DEHP on the mRNA expression levels of (A) Tbx15 and (B) Gpc4 in the subcutaneous and visceral fat of F1 offspring. Results are shown as the mean \pm standard deviation of two independent experiments ( $\mathrm{n}=29$ in the F1 control group and $\mathrm{n}=30$ in the F1 DEHP0.05 group). DEHP, di-(2-ethylhexyl) phthalate. Tbx15, T-box 15; Gpc4, glypican 4 . ${ }^{* *} \mathrm{P}<0.01$ vs. the F1 control group; ${ }^{\# \#} \mathrm{P}<0.01$ vs. subcutaneous fat.

rate was $100 \%$ in the $500 \mathrm{mg} / \mathrm{kg}$ DEHP dose group compared with $0 \%$ in the control and $0.05 \mathrm{mg} / \mathrm{kg}$ DEHP groups. These findings indicate that exposure to DEHP at the TDI level did not affect the reproductive outcomes of mice; however, a high dose of DEHP may damage the reproductive capacity. In addition, $0.05 \mathrm{mg} / \mathrm{kg}$ DEHP exposure did not significantly affect the food intake or reproductive outcome of dams, although it did induce metabolic disorders in the offspring. Previous studies have reported a correlation between in utero exposure to endocrine-disrupting chemicals and the development of metabolic disorders in adulthood $(2,14,25,26)$. In the present study, serum leptin, insulin, serum lipid, and glucose concentrations were significantly elevated in male and female offspring at postnatal week nine, indicating that in utero exposure to DEHP may influence metabolic function in adulthood.

Leptin has an important role in the developmental programming of obesity and insulin resistance (27). In the present study, in utero DEHP exposure correlated with a significant elevation in leptin concentration in F1 offspring, which was consistent with the increased weight of visceral fat. This suggested that in utero DEHP exposure may cause dysregulation of the central effect of leptin in F1 offspring. Similarly, a significant increase in insulin concentration was also demonstrated, consistent with the increase in glucose levels. This implied the potential development of insulin resistance. Elevated leptin and insulin levels in adult offspring may result from hypoleptinemia and hypoinsulinemia during fetal development due to in utero exposure to DEHP (28). Fetal hypoinsulinemia may lead to reduced fetal glucose uptake and subsequent insulin resistance (28). In the present study, leptin and insulin levels were not detected during the fetal period. However, a previous study found that fetal rats exposed to diisobutyl phthalate, another phthalate, exhibited altered insulin and leptin levels, which implies that perinatal phthalate exposure may increase the risk of insulin resistance (27). Rajesh and Balasubramanian (29) also demonstrated that gestational exposure to DEHP may lead to $\beta$-cell dysfunction and whole body glucometabolic abnormalities in F1 offspring.

Fat distribution in F1 offspring in the present study was also affected by in utero exposure to DEHP. The body and subcutaneous fat weights of DEHP-exposed F1 offspring were not significantly increased in male and female mice, whereas the visceral fat weights were significantly elevated. These results indicate that excessive visceral fat storage due to in utero exposure to DEHP may be associated with a high risk of developing metabolic disorders. The present results agreed in part with two previous studies, which demonstrated that direct exposure to DEHP, through placenta and milk, increased body weight and adipose storage in offspring $(13,14)$. However, in contrast to the effects of DEHP on body weight and visceral fat tissue in the F1 offspring observed in the present study, previous studies have detected no effect (3) or reductions (30) in body weight and white adipose tissue, suggesting that developmental exposure to DEHP is unlikely to cause metabolic disorders in adulthood (3). These discrepancies may be due to the use of different exposure dosages, exposure periods (in utero/lactation), or strain differences due to gene mutations or enzyme inactivation accounting for differences in DEHP metabolism (11). Therefore, more extensive studies are required to determine whether there are any adverse effects of DEHP on F1 offspring.

Exposure to certain environmental chemicals, such as diethylstilbestrol may alter the expression of genes involved in fat distribution (31). Overexpression of Tbx15 in 3T3-L1 preadipocytes has been demonstrated to impair adipocyte differentiation and decrease triglyceride content (32). Therefore, differential expression of Tbx15 between fat depots has a principal role in the interdepot differences in adipocyte differentiation, triglyceride accumulation and mitochondrial function, which may contribute to the risk of developing diabetes and metabolic disease (32). Gpc4 is thought to have a critical role in the control of cell growth, differentiation, and morphogenesis (33). This gene is developmentally regulated in 3T3-F442A adipocytes, and its expression level may contribute to the regulation of preadipocyte differentiation (34). Therefore, the expression of Tbx15 and Gpc4 mRNA in subcutaneous and visceral fat tissues was detected in the present study to investigate whether in utero exposure to DEHP may modify their expression levels in F1 offspring. It was demonstrated that $T b x 15$ and Gpc4 mRNA expression levels were significantly increased in subcutaneous fat and visceral fat tissues, respectively, of filial mice exposed to DEHP in utero compared with the control group. DEHP-mediated alteration of developmental gene levels in subcutaneous and visceral fat 
Table II. Spearman correlation coefficient analysis between serum measurements and mRNA expression levels in the fat tissues of F1 offspring.

\begin{tabular}{lllllll}
\hline & \multicolumn{2}{c}{$\begin{array}{c}\text { Subcutaneous } \\
\text { fat }\end{array}$} & & \multicolumn{2}{c}{$\begin{array}{c}\text { Visceral } \\
\text { fat }\end{array}$} \\
\cline { 2 - 3 } Measurement & Tbx15 & Gpc4 & & Tbx15 & Gpc4 \\
\hline Leptin (ng/ml) & 0.164 & 0.120 & $0.317^{\mathrm{a}}$ & $0.290^{\mathrm{a}}$ \\
Insulin (ng/ml) & $0.387^{\mathrm{b}}$ & 0.027 & & 0.027 & $0.423^{\mathrm{b}}$ \\
Total triglyceride (mmol/l) & $0.462^{\mathrm{b}}$ & 0.260 & 0.178 & 0.160 \\
Total cholesterol (mmol/l) & 0.245 & 0.140 & 0.074 & $0.386^{\mathrm{b}}$ \\
Glucose (mmol/l) & $0.303^{\mathrm{a}}$ & 0.208 & 0.113 & $0.305^{\mathrm{a}}$ \\
\hline
\end{tabular}

Tbx15, T-box 15; Gpc4, glypican 4. ${ }^{\mathrm{a}} \mathrm{P}<0.05$; ${ }^{\mathrm{b}} \mathrm{P}<0.01$.

tissues may be one explanation for the excessive visceral fat weight in the DEHP group.

The transcriptional activity and mRNA expression of Tbx15 may be regulated by methylation status in the distal promoter region. Hypomethylation of Tbx15 has previously been correlated with low birth weight, which is a risk factor for the development of obesity in adults (35). In the present study, DNA methylation of Tbx15 was not detected; however, a recent study has reported that gestational exposure to DEHP at $40 \mathrm{mg} / \mathrm{kg}$ may affect the DNA methylation of imprinting genes in fetal germ cells and growing oocytes, and in the offspring's oocytes (36). Therefore, it was inferred in the present study that the differential expression levels of Tbx15 mRNA in subcutaneous and visceral fat tissues between the control and DEHP groups may be due to an alteration in Tbx15 methylation status following in utero DEHP exposure.

Another developmental gene, Gpc4, may be regulated by the ratio of specificity protein 3 to specificity protein 1 (Sp3/Sp1) $(34,37)$. Moreover, there is a physical interaction between $\mathrm{Sp} 1$ and peroxisome proliferator activated receptor- $\gamma$ (PPAR- $\gamma)(38,39)$. The authors of the present study have previously demonstrated that the $\mathrm{Sp} 3 / \mathrm{Sp} 1$ ratio is correlated with $G p c 4$ expression levels in the subcutaneous and visceral fat tissues of mice treated with the PPAR- $\gamma$ agonist, rosigilitazone, indicating that the $\mathrm{Sp} 3 / \mathrm{Sp} 1$ ratio may regulate $G p c 4$ expression during the PPAR- $\gamma$ activation process (37). In the present study, DEHP exposure was associated with a significant increase in Gpc4 mRNA expression levels in visceral fat in F1 offspring, which was consistent with the increase of visceral fat. This suggested that DEHP exposure may affect fat distribution by regulating $G p c 4$ mRNA expression. In animals and humans, intestinal lipases convert DEHP to its monoester equivalent, monoethyl-hexyl-phthalate (MEHP), which is a selective PPAR- $\gamma$ modulator (40). MEHP has previously been demonstrated to induce adipogenesis by modulating PPAR- $\gamma$ activity (41). In utero exposure to a low dose of MEHP significantly increased the body and fat pad weights, and the serum cholesterol, triacylglycerol and glucose levels of male offspring at postnatal day 60 (42). These observations suggest that in utero exposure to DEHP may directly or indirectly regulate the expression levels of $\mathrm{Sp} 1$ and $\mathrm{Sp} 3$ by activating
PPAR- $\gamma$, thereby altering the expression of Gpc4 in visceral and subcutaneous fat tissues.

In conclusion, prenatal exposure to safe, environmentally relevant concentrations of DEHP caused an increase in serum leptin and insulin levels in male and female offspring. This finding indicates that in utero exposure to DEHP may influence metabolic function later in life. The effects of DEHP were analyzed in terms of the increased visceral fat weight and increased expression levels of two developmental genes: Tbx15 in subcutaneous fat and Gpc4 in visceral fat. These data suggest that prenatal DEHP exposure may alter fat distribution by upregulating $T b x 15$ and Gpc4 in subcutaneous and visceral adipose tissues, although the exact mechanisms are yet to be elucidated. The present study stresses the importance of further investigation into the mechanisms by which prenatal and postnatal DEHP exposure may affect fat distribution and lead to metabolic disorders.

\section{Acknowledgements}

This work was supported by the Liaoning Educational Foundation (grant no. L2011138), the Liaoning Natural Scientific Foundation (grant no. 201102285), and the Key Platform Foundation of Science and Technology for the Universities in Liaoning Province, China (grant no. 16010).

\section{References}

1. Kissebah AH and Krakower GR: Regional adiposity and morbidity. Physiol Rev 74: 761-811, 1994.

2. Grün F and Blumberg B: Perturbed nuclear receptor signaling by environmental obesogens as emerging factors in the obesity crisis. Rev Endocr Metab Disord 8: 161-171, 2007.

3. Casals-Casas C, Feige JN and Desvergne B: Interference of pollutants with PPARs: Endocrine disruption meets metabolism. Int J Obes (Lond) 32 (Suppl 6): S53-S61, 2008.

4. Wittassek M, Wiesmüller GA, Koch HM, Eckard R, Dobler L, Müller J, Angerer J and Schlüter C: Internal phthalate exposure over the last two decades-a retrospective human biomonitoring study. Int J Hyg Environ Health 210: 319-333, 2007.

5. Wittassek M, Angerer J, Kolossa-Gehring M, Schäfer SD, Klockenbusch W, Dobler L, Günsel AK, Müller A and Wiesmüller GA: Fetal exposure to phthalates-a pilot study. Int J Hyg Environ Health 212: 492-498, 2009.

6. Serrano SE, Braun J, Trasande L, Dills R and Sathyanarayana S: Phthalates and diet: A review of the food monitoring and epidemiology data. Environ Health 13: 43, 2014.

7. Stahlhut RW, van Wijngaarden E, Dye TD, Cook S and Swan SH: Concentrations of urinary phthalate metabolites are associated with increased waist circumference and insulin resistance in adult US males. Environ Health Perspect 115: 876-882, 2007.

8. Hatch EE, Nelson JW, Qureshi MM, Weinberg J, Moore LL, Singer M and Webster TF: Association of urinary phthalate metabolite concentrations with body mass index and waist circumference: A cross-sectional study of NHANES data, 1999-2002. Environ Health 7: 27, 2008.

9. Buser MC, Murray HE and Scinicariello F: Age and sex differences in childhood and adulthood obesity association with phthalates: Analyses of NHANES 2007-2010. Int J Hyg Environ Health 217: 687-694, 2014.

10. Zhang Y, Meng X, Chen L, Li D, Zhao L, Zhao Y, Li L and Shi H: Age and sex-specific relationships between phthalate exposures and obesity in Chinese children at puberty. PLoS One 9: e104852, 2014.

11. Feige JN, Gerber A, Casals-Casas C, Yang Q, Winkler C, Bedu E, Bueno M, Gelman L, Auwerx J, Gonzalez FJ and Desvergne B: The pollutant diethylhexyl phthalate regulates hepatic energy metabolism via species-specific PPARalpha-dependent mechanisms. Environ Health Perspect 118: 234-241, 2010. 
12. Smerieri A, Testa C, Lazzeroni P, Nuti F, Grossi E, Cesari S, Montanini L, Latini G, Bernasconi S, Papini AM and Street ME: Di-(2-ethylhexyl) phthalate metabolites in urine show age-related changes and associations with adiposity and parameters of insulin sensitivity in childhood. PLoS One 10: e0117831, 2015.

13. Hao C, Cheng X, Guo J, Xia H and Ma X: Perinatal exposure to diethyl-hexyl-phthalate induces obesity in mice. Front Biosci (Elite Ed) 5: 725-733, 2013.

14. Schmidt JS, Schaedlich K, Fiandanese N, Pocar P and Fischer B: Effects of di(2-ethylhexyl) phthalate (DEHP) on female fertility and adipogenesis in $\mathrm{C} 3 \mathrm{H} / \mathrm{N}$ mice. Environ Health Perspect 120: 1123-1129, 2012.

15. Gesta S, Blüher M, Yamamoto Y, Norris AW, Berndt J, Kralisch S, Boucher J, Lewis C and Kahn CR: Evidence for a role of developmental genes in the origin of obesity and body fat distribution. Proc Natl Acad Sci USA 103: 6676-6681, 2006.

16. Yamamoto Y, Gesta S, Lee KY, Tran TT, Saadatirad P and Kahn CR: Adipose depots possess unique developmental gene signatures. Obesity (Silver Spring) 18: 872-878, 2010.

17. Hatch EE, Nelson JW, Stahlhut RW and Webster TF: Association of endocrine disruptors and obesity: Perspectives from epidemiological studies. Int J Androl 33: 324-332, 2010.

18. Lott JA and Turner K: Evaluation of Trinder's glucose oxidase method for measuring glucose in serum and urine. Clin Chem 21 $1754-1760,1975$.

19. Liu L, Gu H, Yang J, Ma S, Yu F, Ren Y and An L: Adipogenic differentiation is not influenced by lentivirus-mediated shRNA targeting the SOCS3 gene in adipose-derived stromal cells. Mol Biol Rep 37: 2455-2462, 2010.

20. Livak KJ and Schmittgen TD: Analysis of relative gene expression data using real-time quantitative PCR and the 2(-Delta Delta C(T)) Method. Methods 25: 402-408, 2001.

21. Naville D, Pinteur C, Vega N, Menade Y, Vigier M, Le Bourdais A, Labaronne E, Debard C, Luquain-Costaz C, Bégeot M, et al: Low-dose food contaminants trigger sex-specific, hepatic metabolic changes in the progeny of obese mice. FASEB J 27: 3860-3870, 2013.

22. Moore RW, Rudy TA, Lin TM, Ko K and Peterson RE: Abnormalities of sexual development in male rats with in utero and lactational exposure to the antiandrogenic plasticizer Di(2-ethylhexyl) phthalate. Environ Health Perspect 109: 229-237, 2001.

23. Lamb JC IV, Chapin RE, Teague J, Lawton AD and Reel JR: Reproductive effects of four phthalic acid esters in the mouse Toxicol Appl Pharmacol 88: 255-269, 1987.

24. Niermann S, Rattan S, Brehm E and Flaws JA: Prenatal exposure to di-(2-ethylhexyl) phthalate (DEHP) affects reproductive outcomes in female mice. Reprod Toxicol 53: 23-32, 2015.

25. Alonso-Magdalena P, Quesada I and Nadal Á: Prenatal Exposure to BPA and offspring outcomes: The diabesogenic behavior of BPA. Dose Response 13: 1559325815590395, 2015.

26. Vaiserman A: Early-life exposure to endocrine disrupting chemicals and later-life health outcomes: An epigenetic bridge? Aging Dis 5: 419-429, 2014.

27. Boberg J, Metzdorff S, Wortziger R, Axelstad M, Brokken L, Vinggaard AM, Dalgaard $M$ and Nellemann C: Impact of diisobutyl phthalate and other PPAR agonists on steroidogenesis and plasma insulin and leptin levels in fetal rats. Toxicology 250 : 75-81, 2008
28. Holemans K, Aerts L and Van Assche FA: Lifetime consequences of abnormal fetal pancreatic development. J Physiol 547: 11-20, 2003.

29. Rajesh P and Balasubramanian K: Gestational exposure to di(2-ethylhexyl) phthalate (DEHP) impairs pancreatic $\beta$-cell function in F1 rat offspring. Toxicol Lett 232: 46-57, 2015.

30. Martinelli MI, Mocchiutti NO and Bernal CA: Effect of di(2-ethylhexyl) phthalate (DEHP) on lipolysis and lipoprotein lipase activities in adipose tissue of rats. Hum Exp Toxicol 29: 739-745, 2010.

31. Newbold RR: Impact of environmental endocrine disrupting chemicals on the development of obesity. Hormones (Athens) 9: 206-217, 2010.

32. Gesta S, Bezy O, Mori MA, Macotela Y, Lee KY and Kahn CR: Mesodermal developmental gene Tbx15 impairs adipocyte differentiation and mitochondrial respiration. Proc Natl Acad Sci USA 108: 2771-2776, 2011.

33. Tumova S, Woods A and Couchman JR: Heparan sulfate proteoglycans on the cell surface: Versatile coordinators of cellular functions. Int J Biochem Cell Biol 32: 269-288, 2000.

34. Li H, Melford K, Judson A and Bensadoun A: Murine glypican-4 gene structure and expression; $\mathrm{Sp} 1$ and $\mathrm{Sp3}$ play a major role in glypican-4 expression in 3T3-F442A cells. Biochim Biophys Acta 1679: 141-155, 2004.

35. Chelbi ST, Doridot L, Mondon F, Dussour C, Rebourcet R, Busato F, Gascoin-Lachambre G, Barbaux S, Rigourd V, Mignot TM, et al: Combination of promoter hypomethylation and PDX1 overexpression leads to TBX15 decrease in vascular IUGR placentas. Epigenetics 6: 247-255, 2011.

36. Li L, Zhang T, Qin XS, Ge W, Ma HG, Sun LL, Hou ZM, Chen H, Chen P, Qin GQ, et al: Exposure to diethylhexyl phthalate (DEHP) results in a heritable modification of imprint genes DNA methylation in mouse oocytes. Mol Biol Rep 41: 1227-1235, 2014.

37. Liu L, Gu H, Zhao Y, An L and Yang J: Glypican 4 may be involved in the adipose tissue redistribution in high-fat feeding C57BL/6J mice with peroxisome proliferators-activated receptor $\gamma$ agonist rosiglitazone treatment. Exp Ther Med 8: 1813-1818, 2014

38. Sassa Y,Hata Y, Aiello LP, Taniguchi Y, Kohno K and Ishibashi T: Bifunctional properties of peroxisome proliferator-activated receptor gammal in KDR gene regulation mediated via interaction with both Sp1 and Sp3. Diabetes 53: 1222-1229, 2004.

39. Sugawara A, Uruno A, Kudo M, Ikeda Y, Sato K, Taniyama Y, Ito $\mathrm{S}$ and Takeuchi K: Transcription suppression of thromboxane receptor gene by peroxisome proliferator-activated receptor-gamma via an interaction with $\mathrm{Sp1}$ in vascular smooth muscle cells. J Biol Chem 277: 9676-9683, 2002.

40. Huber WW, Grasl-Kraupp B and Schulte-Hermann R: Hepatocarcinogenic potential of di(2-ethylhexyl) phthalate in rodents and its implications on human risk. Crit Rev Toxicol 26: 365-481, 1996.

41. Feige JN, Gelman L, Rossi D, Zoete V, Métivier R, Tudor C, Anghel SI, Grosdidier A, Lathion C, Engelborghs Y, et al: The endocrine disruptor monoethyl-hexyl-phthalate is a selective peroxisome proliferator-activated receptor gamma modulator that promotes adipogenesis. J Biol Chem 282: 19152-19166, 2007.

42. Hao C, Cheng X, Xia H and Ma X: The endocrine disruptor mono-(2-ethylhexyl) phthalate promotes adipocyte differentiation and induces obesity in mice. Biosci Rep 32: 619-629, 2012. 